ние каждого из выбранных параметров на показатели дизеля и определить совокупность параметров, обеспечивающих наиболее эффективное использование ВТЭ в дизеле.

\title{
MATHEMATICAL MODELING OF MIXTURIZATION AND CONTAINMENT PROCESSES IN DIESEL ON WATER-FLOOD EMULSION
}

\section{A.V. Savchenko}

The use of water-fuel emulsion (VFE) as a fuel for diesel engines allows to achieve a significant comprehensive improvement of the fuel and environmental performance of the engine. However, the combustion process of VFE emulsion differs markedly from the combustion of conventional diesel fuel. This causes the emergence of reserves to improve the diesel engine at VFE by choosing the optimal parameters. The most rational way to solve this problem is to use the complex mathematical model of a diesel engine when operating on a VFE. One of the most important components of such a diesel model is the mathematical model of the processes of fuel formation and combustion in a cylinder. The article presents the main elements of the mathematical model of processes of mixing and combustion of a water-fuel emulsion in a diesel engine. To identify the mathematical model, the results of a complex of experimental studies of a diesel engine on the water-oil emulsion were used on the most representative operating modes of the diesel engine, reflecting the influence of the fuel intake ahead of the fuel angle, and the water content in the water-oil emulsion. Improved accuracy of data obtained from experimental studies has been achieved using cyclic data processing methods. The results of identification of a mathematical model are presented. The results of mathematical modeling are in good agreement with the experimental data, the nature and degree of influence of the considered factors on the processes of mixing and combustion are reflected adequately. The obtained results are the initial data for modeling the processes of soot and nitrogen oxides formation in a diesel cylinder. This will allow to adequately assess the effect of each of the selected parameters on the diesel performance and determine the set of parameters that ensure the most efficient use of VFE in diesel.

\section{В.В. Калинчак, Т.А. Фудулей, А.К. Копейка, Ю.А. Олифиренко, Д.С. Дараков РАСПРОСТРАНЕНИЕ ПЛАМЕНИ ПО СТРУЕ КАПЕЛЬ ЖИДКИХ ТОПЛИВ}

\begin{abstract}
Принимая во внимание значительные объемы потребления жидких топлив в мировом топливном балансе, одной из актуальных задач современности является сниюение антропогенного влияния на биосферу путем полной или частичной замены минеральных топлив на их возобновляемые аналоги растительного происхождения. В данной работе представлены результаты экспериментальных исследований процесса распространения пламени по одномерной совокупности капель этанола с добавкой воды до 50\% по объему. В отличие от исследований прочессов, сопровождающих горение одиночной капли жидких топлив, горение их совокупности, в виде струи, изучено в меньшей степени. Предложенная схема струйного генератора с вибрирующей иглой, позволяет получить достаточно устойчивую во времени (на протяжении 10 мин.), иепочку монодисперсных капель исследуемого топлива диаметром $d=490 \pm 5$ мкм, с возможностью варьирования межкапельного расстояния. В качестве управляюших параметров для изменения этого расстояния использовались частота колебаний мембраны и величина постоянного давления на резервуар с жидкостью. С использованием разработанной методики проведения эксперимента были получены зависимости относительного расстояния между каплями, от величины постоянного давления на резервуар с жидким топливом, при различных частотах колебаний иглы генератора. Весь процесс распространения фронта пламени по иепочке монодисперсных капель фиксировался на видеосъемку с частотой 300 кадров/сек. Анализ результатов видеосъемки процесса распространения пламени позволил определить зависимость скорости распространения пламени от расстояния между каплями. Анализ качественной картины процесса показал, что с увеличением межкапельного расстояния, скорость распространения пламени падала. Экспериментально определено критическое расстояние между каплями, на порядок превышающее размер капли в условиях эксперимента, при котором прекращалось распространение пламени. Полученные результаты с достаточной степенью достоверности объясняются в рамках предложенного распространения пламени по одномерной системе монодисперсных капель.
\end{abstract}

\section{Введение}

В настоящее время негативное влияние антропогенного фактора на окружающую среду является одной из главных проблем человечества. Одним из способов решения этой проблемы является замена ископаемых топлив на их возобновляемые аналоги [1]. На сегодняшний день, применительно к двигателям внутреннего сгорания, в качестве альтернативы жидким моторным топливам (продуктам нефтеперегонки), хорошо зарекомендовали себя биотоплива второго и третьего поколения (гомоло- ги ряда низших спиртов, метиловые и этиловые эфиры жирных кислот, а также их смеси с бензином и дизельным топливом). Из-за сложности, одновременно протекающих в условиях камеры сгорания физико - химических процессов, очевидно, что простая замена традиционных топлив, на их биологические аналоги, не может выступать в качестве оптимального решения данной задачи, принимая во внимание отличие теплофизических свойств биотоплив и особенности поведения последних в условиях камеры сгорания ДВС. В отли- 
чие от исследований процессов, сопровождающих горение одиночной капли жидких топлив [2,3], изучение горения их совокупности в виде одномерной струи менее исследовано. Как известно [4], необходимым условием для воспламенения капли горючего является образование горючей паровоздушной смеси около его поверхности.

Скорость распространения пламени по струе зависит от таких параметров как: размер капель, составляющих струю; расстояния между ними; константы скорости горения частиц топлива; температура окружающей среды, ее состав и др. [5]. При сжигании жидкого топлива в распыленном состоянии горючая смесь состоит из капель, окруженных газообразным окислителем (гетерогенная или двухфазная смесь) [6]. В таких процессах основным параметром является скорость горения индивидуальной капли в зависимости от их диаметра. В особенности интересен случай, когда диаметр капли меньше характерной ширины зоны прогрева и времени диффузии компонентов в фазе (где находится ведущая стадия горения). В случае больших частиц, скорость горения не зависит от их размера в силу того, что горение распространяется по границе, разделяющей окислитель и горючее.

Данная работа посвящена измерению скорости распространения пламени по струе (одномерной цепочке) капель жидкого топлива, а также определению критического расстояния между каплями в пределе, при котором прекращается распространение пламени.

\section{Методика проведения исследований}

Рассмотрим одномерную цепочку монодисперсных капель жидкости, движущуюся со скоростью $V$ вдоль оси $x$, с фиксированным расстоянием между ними. Поместим в начало координат $(\mathrm{x}=0)$, источник поджига. Если $v$ - скорость распространения пламени движущихся капель, то наблюдаемая скорость движения переднего фронта пламени в лабораторной системе координат, связанной с источником поджига, будет $V+v_{l}$. Значит, при непрерывном действии источника $(\tau \rightarrow \infty)$, фронт пламени будет удаляться на большие расстояния. Регистрируя положения этого фронта $\mathrm{x}_{1}, \mathrm{x}_{2}, \ldots \mathrm{x}_{\mathrm{n}} \ldots$ через определенные промежутки времени $\tau_{1}, \tau_{2}, . . \tau_{n} \ldots$ (при помощи скоростной видеосъемки), можно определить истинную скорость распространения пламени $v_{l}$, если предварительно известна скорость движения капель $V$. Поскольку распространение пламени действует в обоих направлениях от поджигающего центра, то в случае $v<V$ после прекращения действия источника поджига от точки $\mathrm{x}=0$ будет наблюдаться перемещение фронта пламени со скоростью (в лабораторной системе коор- динат) $V-v_{2}$. Фиксируя положения этого фронта пламени, аналогичным способом можно определить $V$ - $v_{2}$ и путем решения системы уравнений для $V-v_{2}$ и $V+v_{l}$ определить величину $v$ как:

$$
v=\frac{v_{1}+v_{2}}{2} \text {. }
$$

Рассмотрим теперь в т. $\mathrm{x}=0$ перидиочески действующий источник поджига, поджигающий струю П-образными импульсами с длительностью поджига $\tau_{1}$, и скважностью $\tau_{2}$. Принципиально возможны два режима работы: при $\tau_{2}>>\tau_{1}$ и $\tau_{2} \approx \tau_{1}$.

Очевидно, что после каждого поджигающего импульса пламя будет одновременно распространятся по цепочке капель как от переднего фронта импульса со скоростью $V+v$, так и от заднего фронта со скоростью $V-v$. Поскольку расстояние между передним и задним фронтами импульса известно и равно $\tau_{1}$, то легко записать положение обоих концов горящего участка струи в некоторый фиксированный момент времени $t$ :

$$
\left\{\begin{array}{l}
x_{1}=(V-v) \cdot\left(t-\tau_{1}\right) \\
x_{2}=(V+v) \cdot t
\end{array} .\right.
$$

Решение этой системы двух уравнений с двумя неизвестными, является:

$$
v=\frac{x_{1}+x_{2}}{2 \tau_{1}} \pm \sqrt{\left(\frac{x_{1}+x_{2}}{2 \tau_{1}}\right)^{2}+V\left(V-\frac{x_{2}-x_{1}}{\tau_{1}}\right)},
$$

где $v$ - скорость распространения пламени, $x_{1}, x_{2}$ - положение концов горящего участка цепи, $\tau_{1}$ - расстояние между передним и задним фронтами импульса, $V$ - скорость одномерной цепочки.

При $\tau_{2}>>\tau_{1}$ на ограниченном условиями эксперимента участке цепочки капель наблюдается перемещение только одного пламени.

При $\tau_{2} \approx \tau_{1}$, наблюдается несколько горящих участков струи. Поскольку передний фронт последующего участка движется с большей скоростью, чем задний фронт предыдущего, то на некотором расстоянии $x^{*}$, наблюдается точка слияния этих двух пламен.

Недостатком этой методики является снижение точности определения скорости при увеличении расстояния между каплями, когда, $v \rightarrow 0$.

Для решения поставленной задачи была собрана экспериментальная установка (рис. 1), используемая для получения цепочки монодисперсных капель.

Экспериментальная установка удовлетворяет следующим требованиям:

- Получение монодисперсной цепочки капель;

- Изменение фиксированного расстояния между каплями;

- Возможность определения размеров капель 
и расстояния между ними;

- Возможность периодического поджига и плавного изменения $\tau_{1}$ и $\tau_{2}$;

- Возможность регистрации скорости распространения пламени.
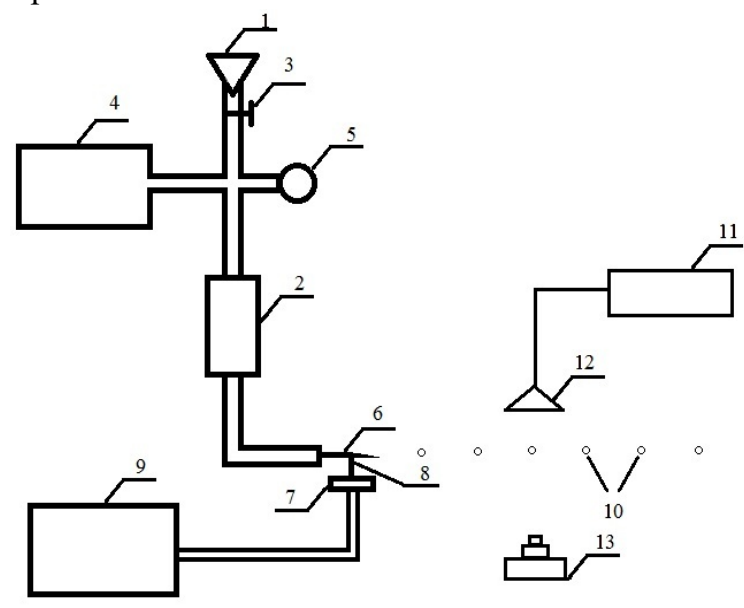

Рис.1. Схема экспериментальной установки: 1 - воронка, 2 - сосуд, 3 -зажим, 4-компрессор, 5 -манометр, 6-медицинская игла, 7 -мембрана, 8 - перемычка, 9 - генератор звуковых сигналов типа ГЗ - 33, 10 - капли, 11 - электронный блок,

12 -осветитель, 13 - видеокамера

Получение монодисперсной цепочки капель осуществлялось следующим образом. Через воронку 1 в сосуд 2, который представляет собой медицинский шприц, наливается жидкое топливо. После этого зажим 3 закрывается. В системе создается давление с помощью компрессора 4, с пределами измерения давления от 0 до $6 \mathrm{\kappa r} / \mathrm{cm}^{2}$. Давление в системе измеряется образцовым манометром 5. Из медицинской иглы 6 , с заточенным острием, вылетает струя топлива. Игла жестко связана с мембраной 7 перемычкой 8 . На мембрану подаются колебания с генератора звуковых сигналов 9 типа ГЗ 33. В результате этих колебаний струя топлива рвется на капли 10 одинакового размера с равными расстояниями между ними. Изменение расстояния между каплями осуществлялось изменением давления компрессора либо изменением частоты звукового генератора.

Для возможности съемки движущейся цепочки капель, использовалась видеокамера - 13, с частотой 300 кадров/сек. Для определения их размеров и расстояний между ними использовалось импульсное освещение капель, создающее стробоскопический эффект. С этой целью использовался тахометр стробоскопический типа 2ТСт 32 - 456, состоящий из электронного блока 11 и осветителя 12.

Капли топлива поджигались спиралью, накал которой регулировался двумя трансформаторами ЛАТР.
Время поджига и задержки задавалось реле времени, которое было собрано по классической схеме «Пульс - Пара», конденсаторы и переменные сопротивления дают возможность регулировать времена замыкания контактов реле, которые, в свою очередь, определяют времена $\tau_{1}$, и $\tau_{2}$. Количественное определение этих времен производилось с помощью осциллографа С1-30.

Поскольку константа скорости горения различных жидкостей изменяется в довольно узких пределах, а критическое расстояние между каплями в струе полностью определяется временем горения одиночной капли, то в качестве модельной смеси использовалась бинарная смесь: этиловый спирт + вода. В самом деле, поскольку этиловый спирт является поверхностно-активным веществом по отношению к воде, в процессе горения происходит разделение составных частей: горючий компонент - спирт оказывается на поверхности капли, а негорючий балласт - вода - внутри нее. При содержаниях воды $50 \%$ по объему в конце выгорания спирта диаметр оставшейся капли составляет $80 \%$ от первоначального. Следовательно, можно считать, что в процессе поджига радиус поджигающей капли в этом случае практически не изменяется.

Основная часть эксперимента проводилась в режиме $\tau_{2}>>\tau_{1}$. Величины $x_{1}, x_{2}$, определялись по анализу видеосъемки. С помощью подборки двух рабочих частот $v_{1}$ и $v_{2}$ тахометра стробоскопического, при которых наблюдалась неподвижная цепочка капель, величина $V$ определялась как:

$$
V=\Delta \cdot v=\Delta \cdot \frac{v_{1} \cdot v_{2}}{v_{1}-v_{2}},
$$

где $V$ - скорость одномерной цепочки, $\Delta$ - расстояние между каплями, $v$ - истинная частота движения капель, $v_{l}$ и $v_{2}$-рабочие частоты

Расстояние между каплями $\Delta$ определялось по видеосъемке и рассчитывалось, как среднее из серии 50 измерений:

$$
\Delta_{c p .}=\frac{\sum_{i=1}^{50} \Delta_{i}}{50},
$$

где $\Delta_{c p .}$ - среднее расстояние между каплями, $\Delta_{i}-$ расстояние между каплями.

На рис. 2 приведен график зависимости относительного расстояния между каплями, диаметр которых $d=490 \pm 5$ мк, от давления при различных частотах возбуждения иглы генератора монодисперсных капель. Как видно из графика при $v=$ const расстояние между каплями растет прямо пропорционально $\sqrt{ } P$, а при $P=$ const, убывает с возрастанием частоты.

Как видим, фиксированное расстояние между каплями можно получить двумя путями: изменяя $P$ при $v=$ const и изменяя $v$ при $P=$ const. Однако при 
небольших $P$ и $v$ генератор работает недостаточно стабильно; кроме того, небольшие скорости частиц приводят к заметному влиянию силы тяжести. С другой стороны, область высоких $P$ ограничена прочностью генератора, а в областях высоких $v$ динамическими особенностями колеблющейся иглы, приводящими к значительной потере мощности. Поэтому каждая реальная конструкция генератора ограничивает расстояние пределами $\Delta_{\min }$ и $\Delta_{\max }$. В нашем случае $\Delta_{\min }=0,64 \mathrm{Mм}$ и $\Delta_{\max }=5,5 \mathrm{mм}$ (для спирта). Погрешность $\delta \Delta= \pm 11,5 \mu \kappa$.

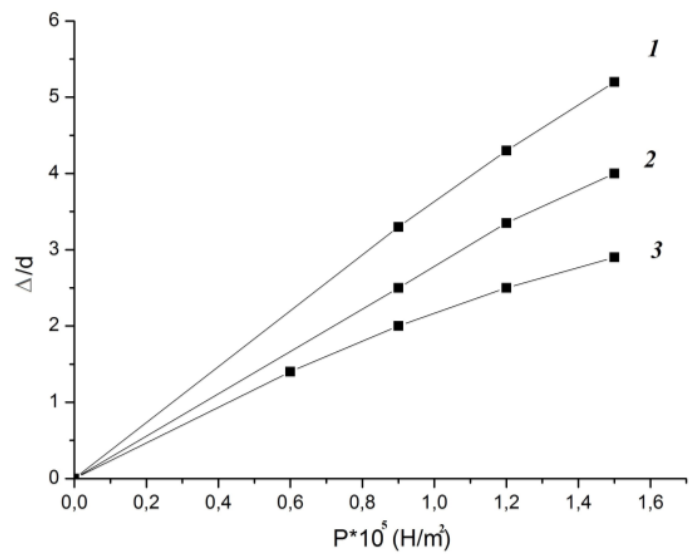

Рис.2. График зависимости расстояния $\Delta / d$ между каплями от давления $P \cdot 10^{5} \mathrm{H} / \mathrm{M}^{2}$ при различных частотах $v$ генератора монодисперсных капель:

$$
1-v=2150 Г u, 2-v=2600 Г u, 3-v=3500 Г u
$$

Величина скорости распространения пламени $v$ находилась из уравнения (1), как среднее серии экспериментов по измерению $x_{1}$ и $x_{2}$, при фиксированных значениях $\Delta$ и $V$.

Экспериментальные значения величины скорости показали, что $\bar{v}=0.208 \mu / c$.

\section{Анализ экспериментального исследования}

На описанной выше установке, по предлагаемой методике, были проведены измерения скорости распространения пламени по цепочке спирта в зависимости от расстояния между каплями. Как видно из графика (рис. 3), скорость распространения $v$ уменьшается с увеличением расстояния между каплями, и, при $\Delta / \mathrm{d}=11$, становится равной 0 . Таким образом, для смеси этилового спирта с водой удалось экспериментально определить критическое расстояние между каплями, при котором прекращается распространение пламени.

Экспериментальное определение критических расстояний, при которых прекращается распространение пламени, показало, что эти расстояния определяются полным временем выгорания горючей компоненты.

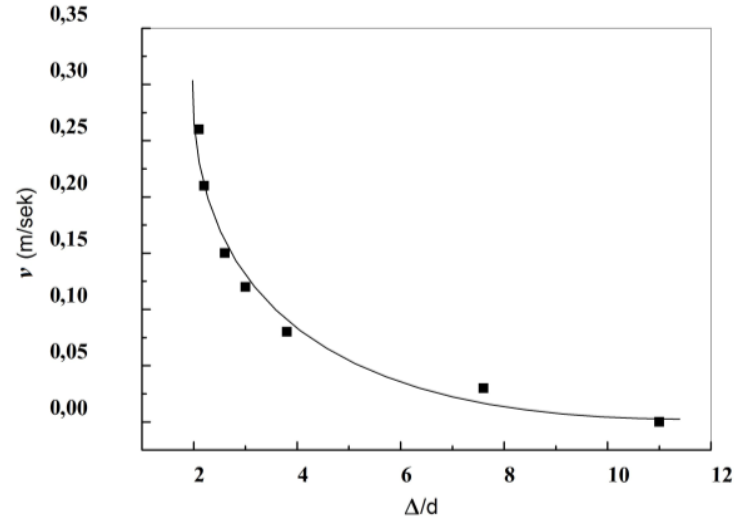

Рис.3. График зависимости скорости распространения пламени $v, \mathrm{~m} / \mathrm{sek}$, от относительного расстояния $\Delta / d$

Таким образом, эти эксперименты позволяют утверждать, что при аналитических расчетах скорости распространения пламени в зависимости от расстояния между каплями, можно пользоваться квазистационарной теорией, не учитывающей изменение радиуса капли, а, следовательно, и радиуса пламени в процессе горения.

\section{Выводы}

Была разработана экспериментальная система получения жидких частиц на основе генератора капель с вибрирующей мембраной.

Разработанная модель генератора дает устойчивую струю монодисперсных частиц в течение нескольких минут, что позволяет использовать её для дальнейших исследований.

Получена зависимость критического расстояния, при котором прекращается распространение пламени и произведены измерения скорости распространения пламени в гетерогенных смесях, состоящих из газообразного окислителя и капель жидкого топлива

\section{Список литературы:}

1. Dukes J.S. Burning buried sunshine human consumption of ancient solar energy / J.S. Dukes // Climatic Change.- 2003. - V.61. - P. 31-44. 2. Дараков Д. С. Горение аэровзвеси капель биотоплива в воздухе / Д. С. Дараков А. Н. Золотко, А. К. Копейка, П. О. Павлюк // Физика горения и взрыва. - 2014. - m. 50, n 5. 3. Hyemin Kim. Combustion of a single emulsion fuel droplet in a rapid compression machine / Hyemin Kim, Seung Wook Baek // Energy 106:422 430.2016. // Energy. 2016. - Vol. 106. - P. 422-430. 4. Хитрин Л.Н. Физика горения и взрыва. / Л.Н. Хитрин. Изд. Московского университета, 19572. 5. Кришеник П.М. Эстафетный режим горения гетерогенных систем / П.М., Кришеник К.Г., Шкадинский // Физика горения и взрыва. - 2005. - T.41. №5. - С.70-76. 6. Вадченко С.Г. Гетерогенная модель распространения пламени / С.Г., Вадченко, А. Г Мержанов. // Докл. АН. - 1997. - Т. 352. № 4. - C. 487-489. 


\section{Bibliography (transliterated):}

1. Dukes J.S. (2003) "Burning buried sunshine human consumption of ancient solar energy." Climatic Chang., vol.61, pp.. 31-44. 2. Darakov, D.S. ,Zolotko A.N., Kopeyka A.K., Pavlyuk P.O. (2014), "Burning of a airsuspension of biofuel droplets in the air" ["Gorenie aerovzvesi kapel biotopliva v vozduhe”], Fizika goreniya i vzryiva, № 5, pp. 27-31. 3. Hyemin Kim Seung Wook Baek, (2016), "Combustion of a single emulsion fuel droplet in a rapid compression machine”. Energy, №106, pp.. 422-430. DOI: 10.1016/j.energy.2016.03.006. 4. Hitrin L.N. (1957), Physics of combustion and explosion [Fizika goreniya $i$ vzryiva]. Izd. Moskovskogo universiteta, 452 p. 5. Krishenik P.M., Shkadinskiy K.G. (2005), "The relay mode of combustion of heterogeneous systems" ["Estafetnyiy rezhim goreniya geterogennyih system"] Fizika goreniya i vzryiva. Vol. 41. №5, pp.. 70-76. 6. Vadchenko S.G., Merzhanov A. G. (1997) "Heterogeneous flame propagation model" ["Geterogennaya model rasprostraneniya plamen"], Dokl. AN. Vol 352, № 4, pp.. 487-489.

Поступила в редакцฺию 30.06.2018 г.

Калинчак Валерий Владимирович - доктор физ.-мат. наук, профессор, заведующий кафедрой теплофизики, Одесский национальный университет им. И.И.Мечникова, Одесса, Украина, e-mail: valerykalinchak@gmail.com.

Фудулей Татьяна Александровна - аспирант кафедры общей и химической физики ФМФИТ «Одесский национальный университет им. И.И. Мечникова», Одесса, Украина, e-mail: tafudulei@gmail.com

Копейка Александр Кузьмич - канд. физ.-мат. наук, доцент, заведующий отделом инноваций и трансфера технологий НИЧ ОНУ, Одесский национальный университет им. И.И.Мечникова, Одесса, Украина, е-таil: kopiyka@onu.edu.ua

Олифиренко Юлия Александровна - аспирант кафедры общей и химической физики, Одесский национальный университет им. И.И.Мечникова, Одесса, Украина, e-mail: olifirenko@icn.od.ua

Дараков Денис Сергеевич - канд. физ.-мат. наук, старший преподаватель кафедры общей и химической физики, Одесский национальный университет им. И.И.Мечникова, Одесса, Украина, e-mail: darakov@onu.edu.ua.

\section{ПОШИРЕННЯ ПОЛУМ'Я ПО СТРУМЕНЮ КРАПЕЛЬ РІДКИХ ПАЛИВ}

\section{В.В. Калінчак, Т.О. Фудулей, О.К. Копійка, Ю.О. Оліфіренко, Д.С. Дараков}

Беручи до уваги значні обсяги споживання рідких палив в світовому паливному балансі, одним із актуальних завдань сьогодення є зниження антропогенного впливу на біосферу шляхом повної або часткової заміни мінеральних палив на їх поновлювані аналоги рослинного походження. У даній роботі представлені результати експериментальних досліджень процесу поширення полум'я по одновимірній сукупності крапель етанолу з добавкою води до 50\% за обємом. На відміну від досліджень процесів, що супроводжують горіння одиночної краплі рідких палив, горіння їх сукупності, у вигляді струменя, вивчено в меншій мірі. Запропонована схема струменевого генератора 3 вібруючою голкою, дозволяє отримати досить стійкий в часі (протягом 10 хв.), ланцюжок монодисперсних крапель досліджуваного палива діаметром $\mathrm{d}=490 \pm 5$ мкм, 3 можливістю варіювання міжкрапельної відстані. В якості керуючих параметрів для зміни цієї відстані використовувалися частота коливань мембрани та величина постійного тиску на резервуар з рідиною. 3 використанням розробленої методики проведення експерименту були отримані залежності відносної відстані між краплями, від величини постійного тиску на резервуар з рідким паливом, при різних частотах коливань голки генератора. Весь процес поширення фронту полум'я по ланцюжку монодисперсних крапель фіксувався на відеозйомку з частотою 300 кадрів/сек. Аналіз результатів відеозйомки процесу поширення полум'я дозволив визначити залежність швидкості поширення полум'я від відстані між краплями. Аналіз якісної картини процесу показав, що зі збільшенням міжкрапельної відстані, швидкість поширення полум'я зменшувалась. Експериментально визначено критичну відстань між краплями, яка на порядок перевищує розмір краплі в умовах експерименту, при якому припинялося поширення полум'я. Отримані результати 3 достатнім ступенем вірогідності пояснюються в рамках запропонованого поширення полум'я по одновимірній системі монодисперсних крапель.

\section{FLAME PROPAGATION IN LIQUID FUEL DROPLETS SPRAY}

\section{V.V. Kalinchak, T.O. Fudulei, O.K. Kopiyka, Yu.O. Olifirenko, D.S. Darakov}

Taking into account the significant volumes of liquid fuels consumption in the world fuel balance, one of the most urgent tasks of our time is to reduce the anthropogenic impact on the biosphere by completely or partially replacing mineral fuels with their renewable plant origin analogues. In this paper we present the experimental studies results of the flame propagation process in a one-dimensional set of ethanol droplets with water addition up to $50 \%$ by volume. In contrast to studies of processes accompanying the combustion of a single liquid fuel droplet, the combustion of their aggregate, in the form of a jet, has been studied to a lesser extent. The proposed scheme of a jet generator with a vibrating needle makes it possible to obtain a chain of monodisperse fuel droplets with a diameter $\mathrm{d}=490 \pm 5 \mu \mathrm{m}$, which is sufficiently stable over time (within $10 \mathrm{~min}$ ), with the possibility of varying the inter-drop distance. As control parameters for changing this distance, the vibration frequency of the membrane and the value of constant pressure on the reservoir with liquid were used. Using the developed experimental procedure, dependences of the relative distance between the droplets, on the value of constant pressure on the reservoir with liquid fuel, at different monodisperse aerosol generator needle oscillation frequencies were obtained.

The whole process of the flame front propagation along the monodisperse aerosol chain was recorded with a frequency of $300 \mathrm{fps}$. The video capturing results analysis of the flame propagation process made it possible to determine the dependence of flame propagation velocity on the distance between the droplets. A qualitative picture process analysis showed the flame propagation velocity decrease along the inter-droplet distance increase. The critical distance between droplets that is an order of magnitude greater than the droplet size under experimental conditions, at which the flame propagation stopped, was determined experimentally. The obtained results are explained with a sufficient degree of reliability within the framework of the proposed relay flame propagation mechanism within a one-dimensional monodisperse aerosol system. 